\title{
Study of polycyclic aromatic hydrocarbons (PAHs) in hydrogen-enriched methane diffusion flames
}

\author{
Chinonso Ezenwajiaku ${ }^{1}$, Midhat Talibi ${ }^{1 *}$, Nguyen Anh Khoa Doan ${ }^{2}$, Nedunchezhian Swaminathan ${ }^{2}$, \\ Ramanarayanan Balachandran ${ }^{1 *}$ \\ ${ }^{1}$ Department of Mechanical Engineering, University College London, Torrington Place, London WC1E 7JE, United Kingdom \\ ${ }^{2}$ Department of Engineering, University of Cambridge, Trumpington Street, Cambridge CB2 1PZ, United Kingdom
}

\begin{abstract}
Polycyclic aromatic hydrocarbons (PAHs) are the carcinogenic components of soot. Detailed understanding of $\mathrm{PAH}$ formation characteristics is required for development of effective strategies to curtail PAH formation and reduce soot in combustion devices. This study presents an experimental methodology to analyse PAH formation characteristics of a non-premixed methane-air flame with and without hydrogen $\left(\mathrm{H}_{2}\right)$ addition, using simultaneous planar laser induced fluorescence (PLIF) imaging of PAH and hydroxyl radical $(\mathrm{OH})$. OH PLIF was used to represent peak temperature regions in the flame front. One-dimensional, opposed-jet laminar non-premixed flame simulations were also carried out for the same fuel mixture conditions. This work describes comparison of trends from both sets of studies. PAH fluorescence intensity values were observed to increase with increasing height above burner, however this rate of increase reduced with $\mathrm{H}_{2}$ addition. This observed rate of change in PAH fluorescence (that is, PAH growth characteristics) is indicative of the sooting potential of the fuel mixture. PAH fluorescence from experiments and PAH concentration from simulation show strong reduction with increase in $\mathrm{H}_{2}$ addition. The percentage reduction in $\mathrm{PAH}$ fluorescence signal with $\mathrm{H}_{2}$ addition closer to the burner tip was of a similar magnitude to that observed with flame simulations. The reduction in PAH with $\mathrm{H}_{2}$ addition could be attributed to the reduction in acetylene and propargyl concentrations, and reduced $\mathrm{H}$-abstraction rates, which reduced the availability of active sites for PAH growth. The proposed experimental methodology for PAH measurements can be readily applied to any fuel mixtures.
\end{abstract}

Keywords: Polycyclic aromatic hydrocarbons; soot; hydrogen; inverse diffusion flames; PLIF; OH

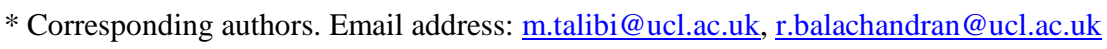




\section{Introduction}

Anthropogenic activities are a major source of air pollution globally due to exhaust emissions from automobiles, aircrafts and industrial plants. Soot has been identified as a particularly toxic emission due to the presence of polycyclic aromatic hydrocarbons (PAHs) that are adsorbed on exhaust soot particles. PAHs are precursors of soot and consist of two or more benzene rings arranged in a variety of configurations. PAHs can persist long-term in the environment, often being carried over long distances without degradation. As an example, PAHs emitted in the UK have been detected as far as southern Norway [1]. Chronic exposure to PAHs is toxic to humans due to their carcinogenic properties by which PAHs induce mutagenic changes in human DNA, resulting in various malignancies, along with other adverse health effects such as weakened immune system and impaired lung function [2,3]. Hence, PAHs have been identified as serious health hazards, with various agencies, such as USEPA (United States Environmental Protection Agency) and IARC (International Agency for Research on Cancer), classifying PAHs with 2-6 rings having the most toxic potential.

In order to develop effective measures to reduce the toxicity of exhaust, it is essential to understand the complex processes which lead to PAH formation, and subsequent soot production. Open flame configurations can provide vital information in this regard, and both premixed and non-premixed flames have been used [4-11]. However, non-premixed flames have been observed to be more suitable to effectively track the early stages of PAH formation (such as acetylene production), and to understand the effect of fuel molecular structure on soot production [12]. In addition, it has also been observed that it is possible to classify PAHs based on their sizes in diffusion flames, which is not feasible in premixed flames [13]. Two types of non-premixed flame configurations are commonly used for PAH studies, normal diffusion flames (NDF) and inverse diffusion flames (IDF); in the NDF configuration the central fuel flow is surrounded by the oxidiser, while the configuration is reversed in IDF. Blevins et al.[14] established the similarity in the chemical and morphological properties of soot formed from both flames. However, investigations have reported difficulties in studying particle precursor formation in NDF because the combustion products convect towards the main reaction zone of the flame and get oxidised [4,5]. On the other hand, the IDF configuration favours the formation of relatively larger amounts of PAHs and soot, as the combustion products get formed on the fuel-rich side of the flame and avoid undergoing significant oxidation. Furthermore, a study by Dobbins [15] observed that nanoparticles sampled from inverse diffusion flames (IDF) had similar chemical composition to those found in diesel engine exhaust. Hence, the IDF configuration is more suitable for the study of PAHs, and relevant to real world combustion applications.

A variety of optical and non-optical techniques exist to study PAHs produced during combustion, and to provide information regarding their speciation and concentrations. The use of the non-intrusive planar laser induced fluorescence (PLIF) technique to detect PAHs in open flames is preferred over intrusive 
techniques (such as collecting samples using microprobes or microfilters), as it does not interfere with the flow field or disrupt concentration profiles [16], and can provide qualitative spatially and temporally resolved details of PAH formation in the flame. Several studies have successfully employed the laser induced fluorescence (LIF) technique in the study of PAH formation [6-8,17]. Liu et al. [9] studied the effect of doping laminar gasoline flames (in a NDF configuration) with various alcohols (methanol, ethanol and n-butanol) on PAHs using PLIF. They observed that increasing the alcohol ratio decreased PAHs monotonously with methanol reported as having most significant effect in inhibiting the PAH growth process. Yamamoto et al. [18] compared the PAH LIF signal with quantitative PAH concentrations obtained using the Gas Chromatography/Mass Spectrometry (GC/MS) sampling technique in a propane flame in IDF configuration. The authors reported a good correlation between the profiles of the PAH LIF signal and the quantitative concentrations of benzene and naphthalene.

Many researchers have investigated experimentally the addition of secondary gases (hydrocarbon and non-hydrocarbon) to hydrocarbon flames to reduce PAH formation [10,11,19-23] and soot [24-31]. Zhang et al. [10] investigated the effect of adding $\mathrm{CO}_{2}$ and water vapour in ethylene/oxygen/argon flames on PAH formation, and reported a monotonic decrease in PAH LIF signal intensities as the proportion of $\mathrm{CO}_{2}$ and water vapour $\left(\mathrm{H}_{2} \mathrm{O}\right)$ were increased. In addition, the authors observed greater PAH reductions with water vapour addition as compared to $\mathrm{CO}_{2}$. The authors suggested the following explanation for this observation. The addition of $\mathrm{CO}_{2}$ reduced the reaction rate of the $\mathrm{CO}+\mathrm{OH} \leftrightarrow \mathrm{CO}_{2}$ $+\mathrm{H}$, depleting the concentration of the $\mathrm{H}$ radical and increasing $\mathrm{OH}$ concentration, thereby enhancing oxidation rates. However, the addition of water vapour reduced the forward reaction rate of $\mathrm{OH}+\mathrm{OH}$ $\leftrightarrow \mathrm{O}+\mathrm{H}_{2} \mathrm{O}$ and $\mathrm{CH}_{3}+\mathrm{OH} \leftrightarrow \mathrm{CH}_{2}{ }^{*}+\mathrm{H}_{2} \mathrm{O}$, resulting not only in increased $\mathrm{OH}$ concentrations, but also reduced benzene concentrations (and hence supressed PAH formation). Wu et al. [11] studied the addition of dimethyl ether (DME) to ethylene-air premixed flames, and concluded that the reduction in PAHs could be attributed to both the increase in the concentrations of oxidising radicals, $\mathrm{OH}$ and $\mathrm{O}$, and the decrease in the amount of carbon that is available to form PAHs. The experimental results were in good agreement with modelling work done in the same study. Park et al. [28] showed that the addition of toluene to $n$-heptane resulted in a linear increase in PAH LIF signal, attributable to the increase in benzyl radicals as the proportion of toluene was increased in the mixture. Hydrogen $\left(\mathrm{H}_{2}\right)$ addition has been found to reduce particulates significantly both in open flame configurations [24,25,27] and combustion engines [32-34]. Previous studies exist which have used computational models to understand PAH growth mechanisms in hydrocarbon flames with $\mathrm{H}_{2}$ addition [26,35] . Guo et al. [26] observed that $\mathrm{H}_{2}$ addition resulted in a reduction in PAHs through both dilution and chemical inhibition effects. The added $\mathrm{H}_{2}$ reduced the concentration of atomic $\mathrm{H}$ in the surface growth region and increased the amount of molecular $\mathrm{H}_{2}$ in the close to the burner surface. This resulted in lower $\mathrm{H}$ abstraction rates in the PAH and soot surface growth processes. This observation was supported by another numerical study conducted by Park et al. [35] which reported that, close to the burner surface, 
the rate of forward reaction of $\mathrm{OH}+\mathrm{H}_{2} \leftrightarrow \mathrm{H}_{2} \mathrm{O}+\mathrm{H}$ increased with increasing $\mathrm{H}_{2}$ addition, thereby increasing the concentration of the $\mathrm{H}$ radical in the reaction zone (and reducing PAH growth). Moreover, it was also observed that the concentration of acetylene was lower close to the burner surface which impeded benzene (and subsequently PAH) formation. The concentration of benzene increased with increasing height above the burner, but the rate of formation of larger PAHs was reported to reduce, attributed to the addition of $\mathrm{H}_{2}$ which decreased $\mathrm{H}$-abstraction rates, and hence reduced the number of sites available for acetylene addition. As outlined in the studies above, hydrogen $\mathrm{H}_{2}$ chemically interferes with PAH formation reactions, and therefore could be a viable candidate for reducing both PAH and soot emissions.

The review of literature shows that while there are a number of computational studies which show a positive effect of adding $\mathrm{H}_{2}$ on soot and $\mathrm{PAH}$ reduction, there is a lack of systematic experimental work to understand the effects of $\mathrm{H}_{2}$ addition on $\mathrm{PAH}$ formation. The current work will focus on developing a methodology to study PAH growth characteristics and, for the first time in the authors' view, present a comparison between experimental and computational studies in methane-hydrogen diffusion flames. The objectives of the current study are: (1) to systematically investigate PAH formation characteristics of non-premixed methane-air flames, (2) to understand the effect of $\mathrm{H}_{2}$ addition on PAH formation in the methane-air flames and (3) to compare the experimental results with 1-D flame simulations utilising detailed chemical mechanisms. The paper first describes the experimental hardware and methodology utilised in this work, before explaining the image processing procedures employed in this work. Details regarding repeatability and comments related to uncertainties in the methodology are then provided. Detailed discussions of experimental and computational results for methane-air and methane-hydrogenair flames are presented before providing a summary of key conclusions. 


\section{Methodology}

\subsection{Burner}

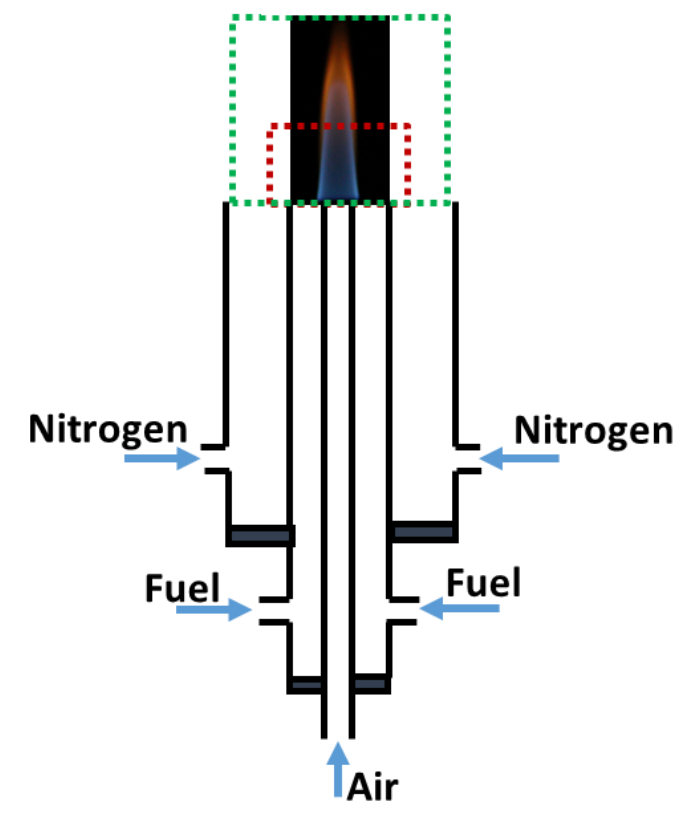

\section{Fuel = Primary $\left(\mathrm{CH}_{4}\right)+$ Secondary $\left(\mathrm{H}_{2}\right)$}

Figure 1: Schematic of the burner showing a typical flame and imaging area for PAH 'zoomed in' (red dotted lines, FOV - $34 \mathrm{~mm} \times 26 \mathrm{~mm}$ ) and 'zoomed out' (green dotted lines, FOV - 76 mm x 56 mm) configurations.

The burner used for this study is based on inverse diffusion flame (IDF) configurations utilised in literature [7,14], and a schematic of the burner is shown in Figure 1. The burner consists of three coaxial stainless steel tubes, with the inner and outer co-flow forming consecutive annular passages around the central tube. The inside diameters of the central, inner co-flow and outer co-flow passages were 10, 30 and $64 \mathrm{~mm}$ respectively. To reduce the effect of rim thickness, the burner exit was tapered to a knife edge for all the three tubes. A combination of steel balls (of diameters $3 \mathrm{~mm}$ and $5 \mathrm{~mm}$ ), wire mesh and honeycomb were utilised for flow smoothening and straightening for the co-flow gases.

The air and fuel passed through central and inner co-flow passages respectively, allowing stabilisation of an inverse diffusion flame, IDF. The flame was shrouded from ambient air by nitrogen, flowing in the outer co-flow passage, to minimise air entrainment effects. The effect of hydrogen $\left(\mathrm{H}_{2}\right)$ addition was studied by premixing desired quantities of $\mathrm{H}_{2}$ considerably far upstream (approximately $1400 \mathrm{~mm}$ ) of the burner exit. Thermal mass flow meters (Vögtlin Instruments) fitted with high precision needle valves were used for independent control and metering of all gas flows (air, methane, hydrogen and nitrogen) to the burner. The accuracy of all the flow meters was $\pm 1.5 \%$ full scale division (FSD). 


\subsection{Simultaneous $\mathrm{OH}$ and $\mathrm{PAH}$ LIF imaging}

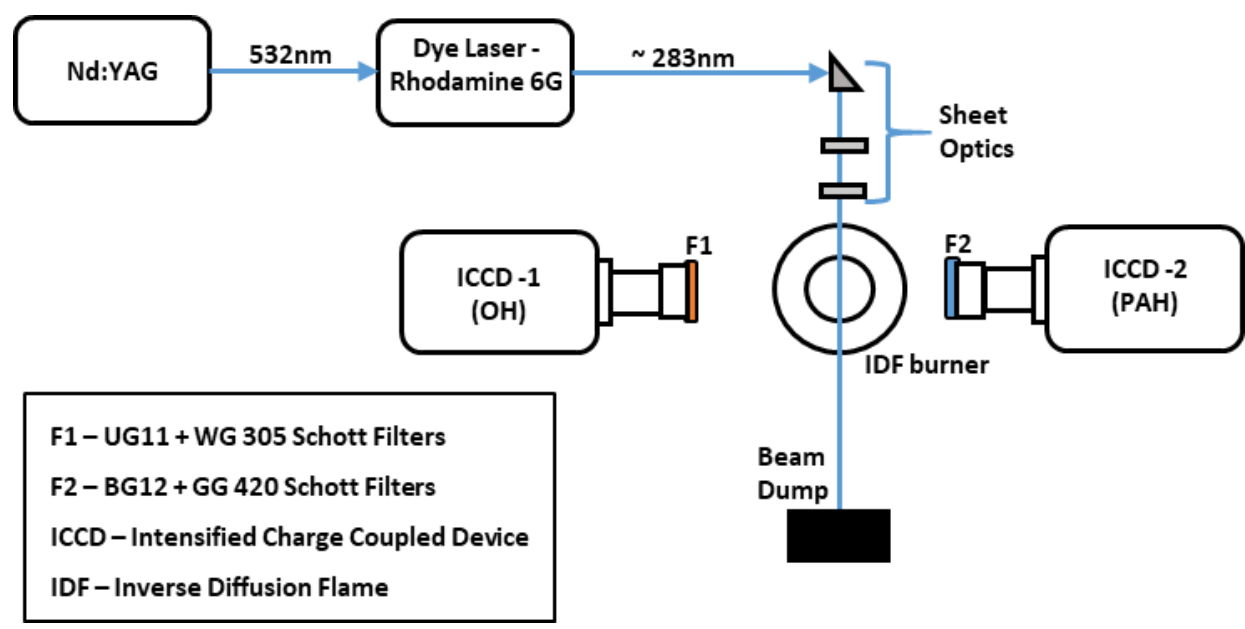

Figure 2: Schematic of the experimental arrangement used for simultaneous planar laser induced fluorescence imaging of PAH and $\mathrm{OH}$.

The schematic for the laser and camera setup is shown in Figure 2. For the excitation of the $\mathrm{OH}$ radical, a frequency-doubled output from an Nd:YAG Laser (Litron Nano-PIV) was used to pump a tunable dye laser (Fine Adjustments Pulsare-S model) with Rhodamine 6G dye. The output from the dye laser was frequency-doubled and tuned to near $283 \mathrm{~nm}$ to obtain the Q1(5) transition of the $A^{2} \Sigma^{+} \leftarrow$ $X^{2} \Pi(1,0)$ band with approximately $12 \mathrm{~mJ}$ pulse energy. A combination of a right-angle prism, planoconcave cylindrical lens $(\mathrm{f}=-40 \mathrm{~mm})$ and bi-convex lens $(\mathrm{f}=500 \mathrm{~mm})$ was used to convert the beam to a light sheet with height of $50 \mathrm{~mm}$ and thickness of $0.15 \mathrm{~mm}$ determined by the scanning knife edge technique [5]. The location of the sheet was adjusted to coincide with the central axis of the burner.

The same laser sheet was also used for excitation of the PAH species. It was noted from literature that PAH LIF emissions are insensitive to excitation wavelength in the range between 265 and $297 \mathrm{~nm}$ [36]. The interference from soot particles, due to resonant radiation from laser induced incandescence, on PAH LIF measurement in diffusion flames is well-known [21,29,37,38]. A simple soot isolation technique, described in [39], was used to measure the amount of soot present in the flames; no interference from soot was observed at the flow conditions used in this study in the region of interest (ROI).

The fluorescence from the $\mathrm{OH}$ radicals and PAH species were imaged simultaneously by two intensified charge coupled devices (ICCDs) placed perpendicular to the direction of the laser sheet on either side of the burner (Figure 2). The OH fluoresced near $310 \mathrm{~nm}$ and was captured on ICCD-1 (see Figure 2) which was fitted with a UV $100 \mathrm{~mm}$ f/2.8 Cerco lens and a combination of UG11 and WG305 Schott glass filters. 
For the PAH species, the fluorescence was captured on ICCD-2 (Figure 2) using lens of two different focal lengths. A f/2.8 Nikon lens of focal length $105 \mathrm{~mm}$ was used to image a larger part of the flame (FOV- $76 \mathrm{~mm} \times 56 \mathrm{~mm}$ ) with a pixel projection resolution of $25 \mu \mathrm{m}$. While, a f/1.2 Nikon lens of focal length $50 \mathrm{~mm}$ was used to image up to $26 \mathrm{~mm}$ of the flame height hence providing a higher resolution image of the lower part of the flame closer to the burner lip (FOV- $34 \mathrm{~mm} \times 26 \mathrm{~mm}$, pixel projection resolution- $56 \mu \mathrm{m})$. The two focal length arrangements will from here on be referred as the 'zoomed out' and 'zoomed in' configurations, and have been illustrated in Figure 1 using green and red dotted lines, respectively. A combination of GG420 (high pass Schott filter) and BG12 (low pass Schott filter) fitted to the lens to image fluorescence from PAH species of three or more rings between the wavelength range of $420 \mathrm{~nm}$ and $480 \mathrm{~nm}$.

The emitted PAH LIF spectra are heavily influenced by variations in temperature and the concentration of species in the surrounding atmosphere [40]. Hence, it is not yet possible to determine the concentrations of individual PAH species based on the emitted fluorescence signal [41]. Rather, the obtained LIF signal collectively represents a mixture of PAH species, often differentiated for specific sizes based on the collection wavelength range. Most PAH species absorb strongly over a wide range of excitation wavelengths from UV to visible $[13,42]$ with the corresponding emission wavelength dependent on the number of aromatic rings possessed by the PAH molecule, and increasing with the number of aromatic rings [11,21,43]. Vander Wal et al. [44] reported that with excitation wavelength below $300 \mathrm{~nm}$, PAH with 2 or 3 aromatic rings can fluoresce between 300-350 nm while PAHs of 4 rings or more can exhibit fluorescence in the range $300-700 \mathrm{~nm}$. More specifically, investigations in $[11,43]$ assigned PAH fluorescence in the visible range of $400-480 \mathrm{~nm}$ to larger PAHs of 3 to 5 rings.

The temperature dependence of a given PAH LIF signal primarily arises from the collisional quenching and the Boltzmann population fraction [45]. Since the LIF signal being obtained in this work represents a mixture of PAHs of three to five rings, the absorption and emission spectral characteristics of the PAHs can be assumed to be largely similar. There is no data available in literature outlining the variation in the quenching characteristics of PAH species with temperature in the range of interest $[37,46]$. However, flame simulation analysis performed for this work shows that the peak PAH occurs at a narrow temperature range $(1540 \pm 20 \mathrm{~K})$ for all the $\mathrm{H}_{2}$ addition levels considered in this study - the data has been presented in Table 1. It was also observed from the flame simulation studies that the range of temperature remained similar for the different $\mathrm{H}_{2}$ addition cases, and therefore it can be assumed that the Boltzmann constant would remain constant for the different test cases. In this study, it has been assumed that the quenching characteristics would remain constant for all the experiments conducted in this study. Hence, it can be concluded that the PAH LIF signal would be primarily dependent on the number density of the PAH species present in the flame. Furthermore, the PAH LIF technique will be suitable for this work as it focusses on the relative comparison in PAH formation characteristics with different levels of $\mathrm{H}_{2}$ addition. 


\subsection{1-D Flame calculations}

To model the flame structure in regions away from the heat loss region and the top curved region of a laminar inverse diffusion flame, counter-flow laminar flames calculations at a pressure of 1 atm have been performed using CANTERA [47]. The chemical reactions are modelled using the AppelBockhorn-Frenklach gas-phase mechanism [48]. This mechanism was used as it includes some aromatic species and has been well validated for $\mathrm{C}_{1}-\mathrm{C}_{2} /$ air combustion. The fuel stream for the counter-flow was composed of $\mathrm{CH}_{4}$ or $\mathrm{CH}_{4}$ enriched with $\mathrm{H}_{2}$ depending on the case under study, while the oxidiser stream was air. Both streams were set at a temperature of $298 \mathrm{~K}$, and, for all cases, the strain rate was set to a small value (below $10 \mathrm{~s}^{-1}$ ) to ensure a fully reacting solution which is of interest here. These computational calculations obtained allowed for qualitative comparison with the experimental results.

\subsection{Flow conditions}

\begin{tabular}{|c|c|c|c|c|c|}
\hline $\begin{array}{c}\mathrm{H}_{2} \text { addition } \\
(\mathrm{lpm})\end{array}$ & $\begin{array}{c}\% \mathrm{H}_{2} \\
\text { addition }\end{array}$ & $\begin{array}{c}\mathrm{T} \text { at } \\
{[\mathrm{PAH}]_{\max }} \\
(\mathrm{K})\end{array}$ & $\begin{array}{c}\mathrm{T}_{\max } \\
(\mathrm{K})\end{array}$ & $\begin{array}{c}w_{\mathrm{OH}} \\
\text { experiments } \\
(\mathrm{mm})\end{array}$ & $\begin{array}{c}w_{\text {OH }} \\
\text { simulations } \\
(\mathrm{mm})\end{array}$ \\
\hline 0 & 0 & 1520 & 2152 & 2.61 & 3.41 \\
\hline 0.2 & 2 & 1530 & 2159 & 2.51 & 3.41 \\
\hline 0.4 & 4 & 1540 & 2165 & 2.50 & 3.27 \\
\hline 0.6 & 6 & 1550 & 2171 & 2.51 & 3.41 \\
\hline 0.8 & 8 & 1520 & 2178 & 2.44 & 3.41 \\
\hline 1 & 10 & 1540 & 2184 & 2.56 & 3.55 \\
\hline 1.2 & 12 & 1550 & 2190 & 2.91 & 3.62 \\
\hline 1.4 & 14 & 1560 & 2196 & 2.83 & 3.41 \\
\hline 1.6 & 16 & 1530 & 2202 & 2.69 & 3.48 \\
\hline 1.8 & 18 & 1540 & 2208 & 2.98 & 3.62 \\
\hline 2 & 20 & 1550 & 2213 & 2.81 & 3.69 \\
\hline
\end{tabular}

Table 1: Hydrogen flow rates $\left(Q_{\mathrm{H}_{2}}\right)$ at corresponding percentage $\mathrm{H}_{2}$ addition $\left(Q_{\mathrm{H}_{2}} / Q_{\mathrm{CH}_{4}}\right)$ for fixed $Q_{\mathrm{CH}_{4}}(10$ lpm) and $Q_{\text {air }}(1.5 \mathrm{lpm})$ flow rates. The temperature at maximum PAH concentration ( $T$ at $\left.[\mathrm{PAH}]_{\max }\right)$ and the maximum flame temperature $\left(T_{\max }\right)$ is also shown for each $\mathrm{H}_{2}$ addition.

For all the tests conducted in this study, the flow rate of methane $\left(\mathrm{CH}_{4}\right), Q_{C H 4}$, and of air, $Q_{\text {air }}$, were fixed at $10 \mathrm{lpm}$ and $1.5 \mathrm{lpm}$, respectively. Hydrogen $\left(\mathrm{H}_{2}\right)$ was added to the $\mathrm{CH}_{4}$ flow line, well in advance of the flame location to ensure proper mixing. The flow rate of hydrogen $\left(Q_{H 2}\right)$ was changed with the resolution of $0.2 \mathrm{lpm}$. Up to $2 \mathrm{lpm}$ of $\mathrm{H}_{2}$ was added to the $\mathrm{CH}_{4}$, which is $20 \%$ by volume of $\mathrm{CH}_{4}$. The same mole fraction of fuel mixture (methane and hydrogen) served as input to 1D flame calculations. In addition, Table 1 also shows the temperature at maximum PAH and the maximum temperature, both obtained from the flame simulation work. These temperatures will be referred to in later sections of the paper. 


\section{Image processing}

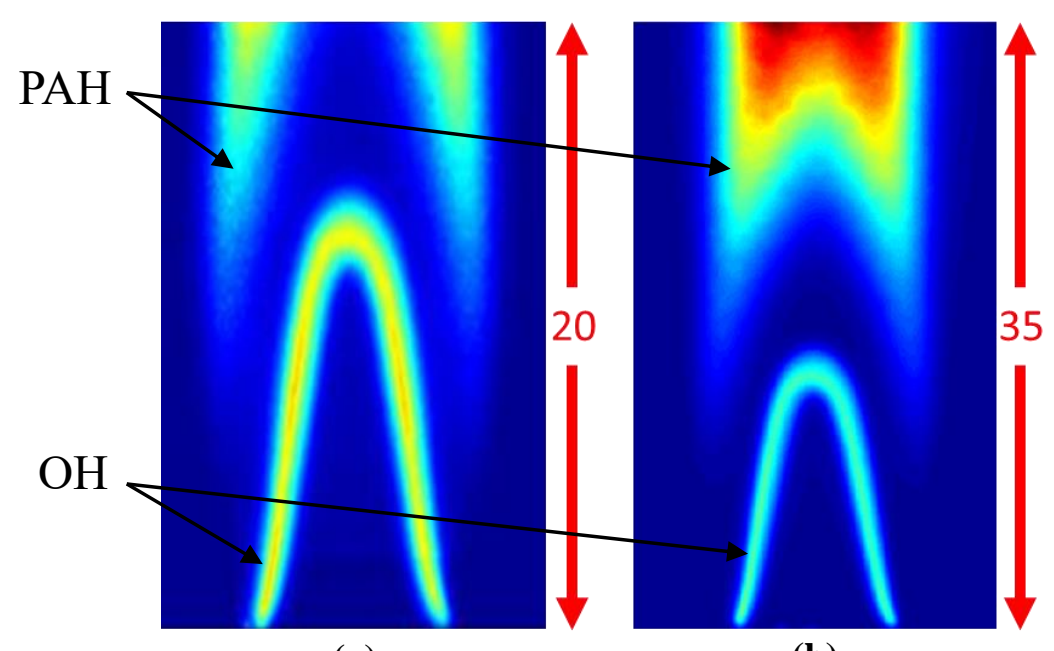

(a)

(b)

Figure 3: Illustrations showing resolution-adjusted, averaged and combined PLIF images of OH and PAH for the (a) zoomed in and (b) zoomed out configurations (only the region of interest, ROI, is shown).

Figure 3 shows the averaged combined images of PAH and $\mathrm{OH}$ for the two different focal length imaging arrangements, zoomed in and zoomed out (as described in Section 2.2). It should be noted that the captured LIF images have been cropped to only show the region of interest (ROI) in Figure 3. The PAH and OH LIF images were captured by two separate ICCD cameras (see Figure 2), with 400 instantaneous images captured for each test condition. A software median filter was used on the instantaneous images to reduce noise. The filtered instantaneous images were then background corrected and averaged to obtain averaged $\mathrm{PAH}$ and averaged $\mathrm{OH}$ images for each test condition. As the pixel projection resolution of $\mathrm{OH}$ and $\mathrm{PAH}$ images are different, the $\mathrm{OH}$ image was then transposed (with sub-pixel accuracy) onto the PAH image using an in-house developed image warping MATLAB® code. The resolution-adjusted images of $\mathrm{OH}$ and $\mathrm{PAH}$ had common coordinates and were kept separately for further processing to obtain information regarding PAH formation characteristics. The combined images are presented in Figure 3 (the purpose of the illustration is to show spatial alignment, hence the colour scales are arbitrary). Two different image processing approaches were employed to obtain PAH formation characteristics, as described in the following sections. 


\section{1. $\quad$ Change in PAH with respect to flame position (flame normal statistics)}

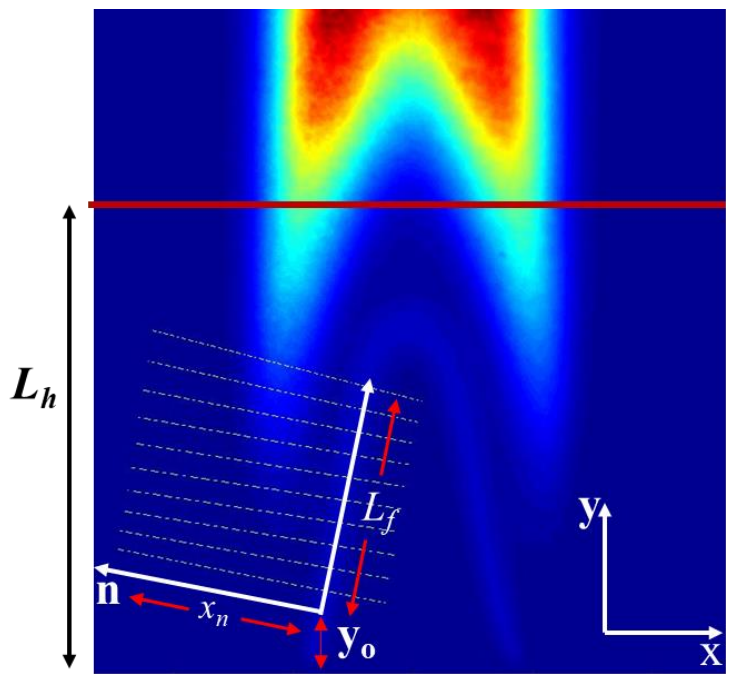

(a)

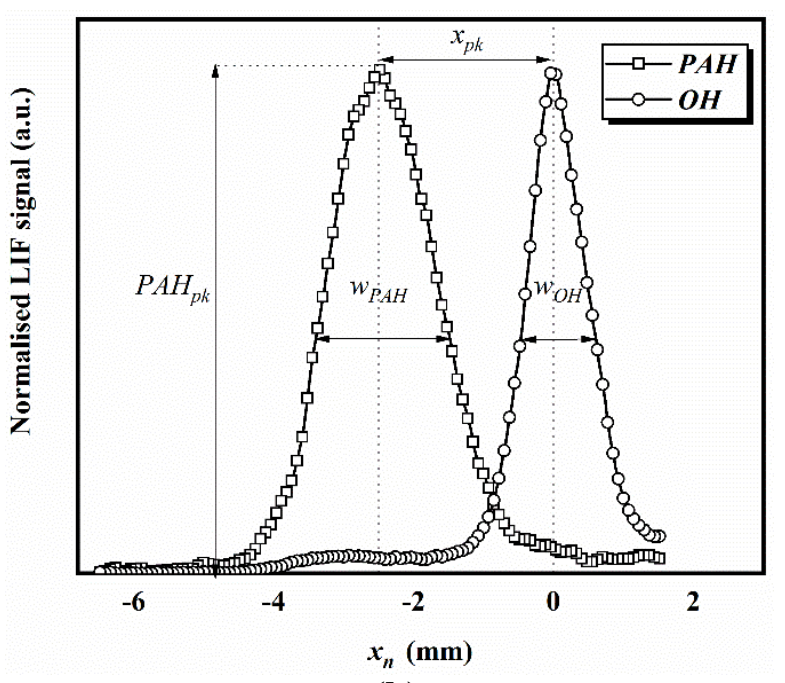

(b)

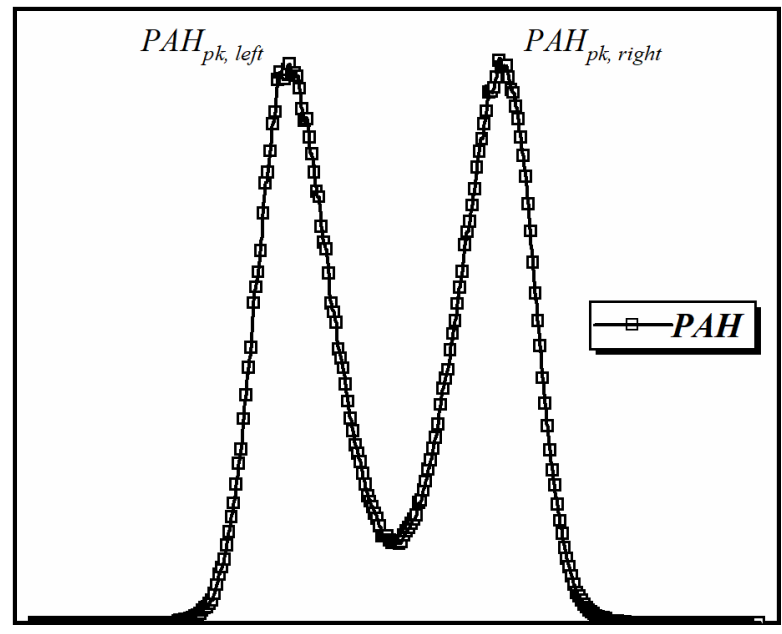

(c)

Figure 4: (a) Typical PAH and OH combined LIF image showing the various coordinate systems under consideration, (b) PAH and $\mathrm{OH}$ line profile along the normal ' $\mathrm{n}$ ', at a representative distance of $8 \mathrm{~mm}$ along the flame front $\left(L_{f}\right)$ (c) PAH line profile at height $20 \mathrm{~mm}$ (at $\mathrm{y}=L_{h}$ in Fig.4a) above the burner lip.

PAH formation is a pyrolytic process, thermal and mass transport effects have a strong influence on PAH concentration profiles. In addition, as the current study utilises hydrogen, which is a relatively fast molecule as compared to methane and air, preferential diffusion effects of molecules can also have significant effects on PAH formation. In non-premixed flames, the peak temperature region coincides with peak $\mathrm{OH}$ concentration [49]. Due to the non-availability of well-resolved temperature data, $\mathrm{OH}$ will be used as a substitute to denote peak temperature regions. Hence, as one of the image processing approaches, the PAH profiles will be presented based on peak $\mathrm{OH}$ location (representing the flame location, that is, peak temperature regions), which would allow meaningful comparison with 1-D simulation. 
The reference flame location was evaluated based on the loci of the peak of the OH LIF profile at different heights (referred to as the flame front). A combined ( $\mathrm{OH}$ and PAH) LIF image is shown in Figure $4 \mathrm{a}$, annotated with the different characteristic parameters used in this work. ' $L_{f}$ ' is the length along of the flame front with respect to a chosen initial height (as shown in Figure 4a), starting at a distance ' $y_{0}$ ' (where $y_{o}=1.85 \mathrm{~mm}$ ) above the burner tip. The PAH profile was then determined by walking along a perpendicular axis, $n$, at every reference location (that is, at various flame front locations ' $L_{f}$ ' along the flame front). ' $x_{n}$ ' indicates distance normal to the flame front (as shown in Figure $4 a$ ), and will be used to describe PAH profiles normal to the flame front. The inter-peak distance or peak location $\left(x_{p k}\right)$ refers to the distance from the flame front to the maximum PAH LIF signal. The widths of the PAH $\left(w_{P A H}\right)$ and $\mathrm{OH}\left(w_{O H}\right)$ are defined using the full-width half maximums (FWHMs) of their respective profiles. Both parameters, $x_{p k}$ and $w_{P A H}$, were normalised with $w_{O H}$ along $L_{f}$, and have been illustrated in Figure 4b. The change in PAH peak, $P A H_{p k}$, (or the cumulative, referred as ' $P A H_{\text {sum }}$ ') of the PAH profile with increasing $L_{f}$ provided PAH formation characteristics in these flames. The $P A H_{\text {sum }}$ refers to the total amount of PAHs (cumulative of PAH profile) along the flame normal, at any given distance along the flame front, $L_{f} . P A H_{\text {sum }}$ incorporates any variation in peak-to-peak distance $\left(x_{p k}\right)$, PAH profile width $\left(w_{P A H}\right)$ or profile shape at different $L_{f}$.

\subsection{Change in PAH with vertical height above burner lip}

The second image processing approach involved presenting the change in PAH concentration with respect to the vertical height above the burner lip, independent of the flame location. This is because the flame front (represented by the $\mathrm{OH}$ profile) only exists up to about $15 \mathrm{~mm}$ vertically above the burner tip, and hence to observe PAHs at higher heights it was better to consider the PAH signal independent of the flame front. Figure 4a shows the ' $x$ ' and ' $y$ ' axis, which refer to the horizontal and vertical Cartesian co-ordinates with respect to the centre of the burner lip. Figure $4 \mathrm{c}$ shows a typical line profile at a vertical height of $20 \mathrm{~mm}$ above the burner lip; the location of the line profile is shown by the red line (at a height $\mathrm{y}=L_{h}$ ) on Figure $4 \mathrm{a}$. A good symmetry can be observed between the LIF signal profile for each side of the flame, providing confidence in the axisymmetric nature of the flame.

From here onwards, the PAH LIF signal and the concentration of PAH (from flame simulation studies) will be referred to as $P A H$ and [PAH] respectively. Similarly, the $\mathrm{OH}$ will be denoted by $\mathrm{OH}$ and $[\mathrm{OH}]$. $P A H_{p k}$ refers to the maximum LIF signal (profile peak along ' $\mathrm{x}$ ' and ' $\mathrm{n}$ ' axes) for each side of the flame, left and right, while $P A H_{\text {sum }}$ refers to the cumulative LIF signal for both sides of the flame.

\section{Uncertainty and errors}


The repeatability of the methodology was verified by performing the same experiments (i.e., using the same test conditions) several times on different days, and the variability in the PAH LIF signals ( $P A H_{p k}$ and $\left.P A H_{\text {sum }}\right)$ was determined to be less than $1 \%$. In addition, in order to understand the relationship between laser intensity and PAH LIF signal, a preliminary set of tests were conducted whereby the laser energy was incrementally increased from $3 \mathrm{~mJ}$ to $12 \mathrm{~mJ}$, and the PAH LIF signal was found to be independent of laser intensity beyond $8 \mathrm{~mJ}$ laser energy. Similar observations regarding saturation of PAH fluorescence to variation in laser fluence have been reported in literature [38]. For this study, the laser energy was kept at $10 \mathrm{~mJ}$, with the laser shot-to-shot energy variations observed to be within \pm $10 \%$. This implies that the observed variations in laser energy (that is, $10 \pm 1 \mathrm{~mJ}$ ) are still above the threshold value $(8 \mathrm{~mJ})$ for PAH fluorescence saturation. Hence, it can be concluded that the observed differences in PAH LIF signal are independent of fluctuations in laser energy.

To ascertain the effect of the number of images being averaged on the PAH LIF signal and associated noise, up to 800 images were accumulated for the base test condition (methane-only condition), and averages of different number of images were determined. It was concluded that an average of 200 images was sufficient for reliable data analysis, and beyond that point any variation in the signal was negligible. The estimated fluctuations in the distribution of the peak value and the corresponding location was within 3\% for the $\mathrm{OH}$ and $5 \%$ for the $P A H$, for all test cases. Furthermore, the signal to noise ratio (SNR) evaluated for various conditions ranged from 15 to 18 for $\mathrm{OH}$ and 12 to 20 for $P A H$, with higher SNR for the zoomed in imaging configuration relative to the zoomed out configuration. 


\section{Results and discussion}

\subsection{Methane-air flame formation characteristics}

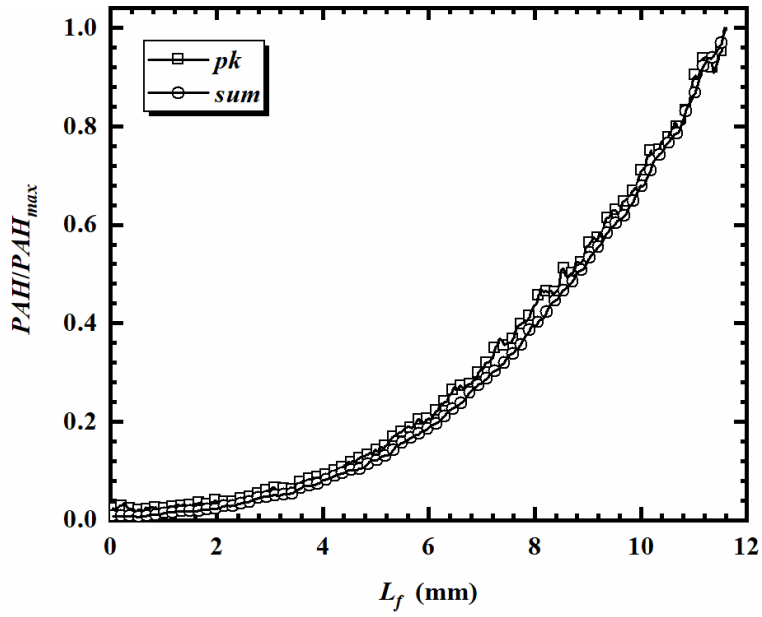

(a)

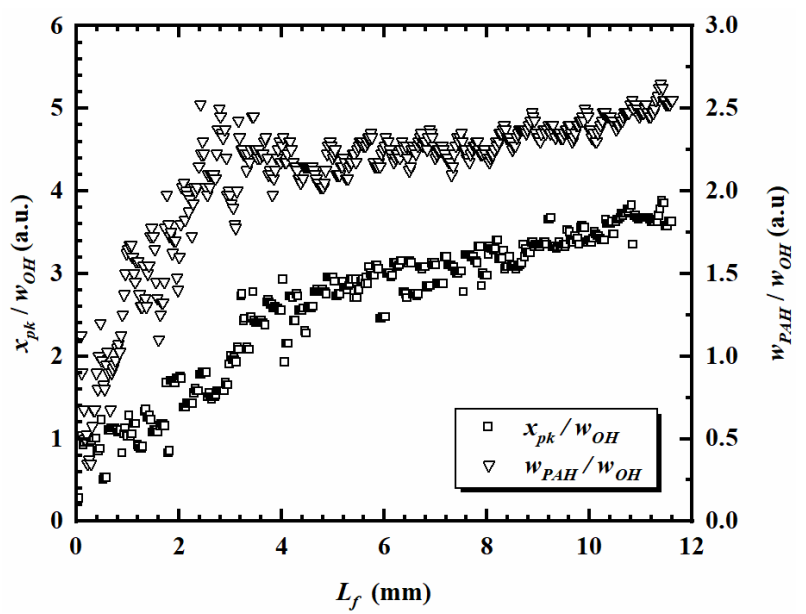

(b)

Figure 5: (a) Variation in normalised inter-peak PAH LIF signal $\left(P A H_{p k}\right)$ and the cumulative sum of the PAH line profile $\left(P A H_{\text {sum }}\right)$ as a function of length along the flame front $\left(L_{f}\right)$, and (b) variation in interdistance between OH peak and PAH peak $\left(x_{p k}\right)$, and the PAH profile width $\left(w_{P A H}\right)$, normalised with $w_{O H}$, at various $L_{f}$.

Figure 5a shows the change in the peak PAH LIF signal $\left(P A H_{p k}\right)$ and the cumulative sum of the PAH line profile $\left(P A H_{\text {sum }}\right)$ as a function of ' $L_{f}$ ', the distance along the flame front, for the zoomed in imaging configuration. The results shown in Figure 5a are for the methane-air test conditions only, without any addition of $\mathrm{H}_{2}$. It can be seen that $P A H$ increases non-linearly with increasing length along the flame front. The LIF signal from PAH depends on both the number density of each type of PAHs (that is, the PAH concentration), and the structure of the PAH molecule. It is generally known from literature, that larger PAH rings fluoresce with a higher intensity $[13,36,50]$. Hence, in addition to the increase in the concentration of the PAHs, the increase in LIF signal could also be due to the smaller PAHs combining and growing into larger rings further downstream in the flame. It is pertinent to note that since it was not possible to discriminate between individual PAHs, the signal shown here is only a qualitative indication of PAH formation characteristics in the flame, as described earlier.

Figure $5 \mathrm{~b}$ presents the variation in the normalised inter-peak distance $\left(x_{p k}\right)$ and the normalised PAH profile width $\left(w_{P A H}\right)$ with increasing distance along the flame front, $L_{f} ; x_{p k}$ and $w_{P A H}$ were normalised using $w_{O H}$ of the respective profile. The inter-peak distance indicates how far from the flame front does maximum PAH concentration occur with the flame front represented by the loci tracing the peak $\mathrm{OH}$ concentration. As explained earlier, the peak $O H$ can be approximated to the peak temperature regions with considerable accuracy for non-premixed flames. It can be seen from the figure that inter-peak distance increases almost monotonically with ' $L_{f}$ '. However, the profile width $\left(w_{P A H}\right)$ increases significantly till about $4 \mathrm{~mm}$ along the flame front. Up to $4 \mathrm{~mm}$, the signal intensity is weak and the 
signal-to-noise ratio (SNR) is relatively low, due to low levels of PAH present and the limitations of the imaging system. Furthermore, the effects of heat loss are more significant close to the lip of the burner. Above $4 \mathrm{~mm}$, the width increases, but not as sharply, indicating the role of continued production of PAHs. As evidenced from 1D flame simulations, PAH production is restricted to a fixed temperature range irrespective of $\mathrm{H}_{2}$ addition levels (see Table 1), the change in $x_{p k}$ and the $w_{P A H}$ with increasing $L_{f}$ indicates the effect of residence time. It should also be noted that the similarity in trends of $P A H_{\text {sum }}$ and $P A H_{p k}$, as observed in Figure 5a, exists because the profile width remains largely the same above $4 \mathrm{~mm}$. Hence, only the height of the PAH profile was changing, with increasing length along the flame front, denoting higher LIF signal.

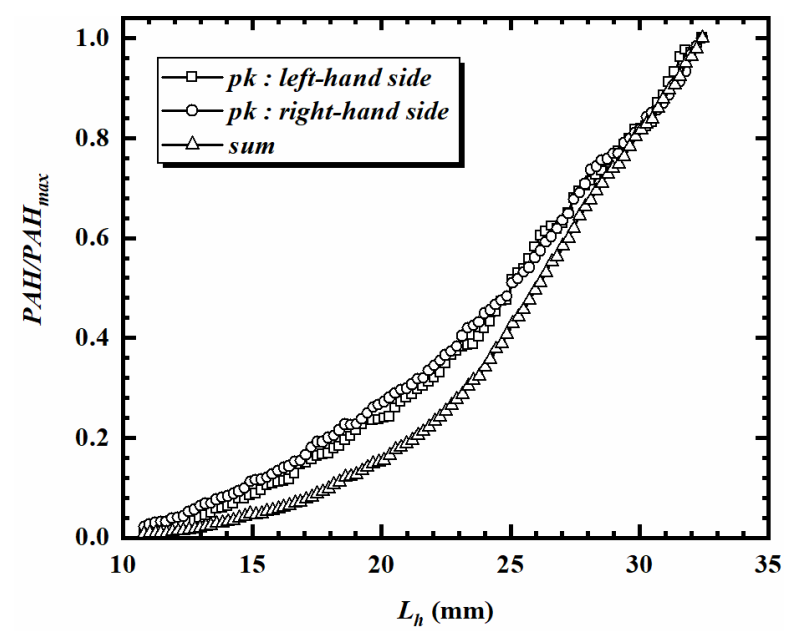

Figure 6: Peak PAH LIF signal $\left(P A H_{p k}\right)$ for the left and right sides of the flame, and the cumulative sum of PAH line profile $\left(P_{A} H_{\text {sum }}\right)$ as a function of the vertical height $\left(L_{h}\right)$ above the burner lip.

Figure 6 shows the change in the peak PAH LIF signal $\left(P A H_{p k}\right)$ and the cumulative line profile $\left(P A H_{\text {sum }}\right)$, as a function of vertical height, $L_{h}$, above the burner tip, for the zoomed out camera configuration. Similar to Figure 5a, this figure also shows a monotonic increase in both $P A H_{p k}$ and $P A H_{\text {sum }}$ with increasing distance from the burner lip. Similar trends of PAH concentration with respect to height above the burner have been observed in previous studies [49,51,52]. For the zoomed out configuration, since the camera lens was placed further away from the burner (in order to look at PAHs higher up the flame), the amount of light entering the camera lens from the flame was reduced (following the inverse square law relation between intensity and distance from the light source). Hence, no appreciable PAH signal was observed below $L_{h}=11 \mathrm{~mm}$ for this configuration. It can also be observed from Figure $6 \mathrm{a}$ that both the magnitude and variation in $P A H_{p k}$ evaluated for both sides of the flame (left and right) are similar, which confirms the axisymmetric nature of the burner. Hence, from here onwards, results from only one side of the flame will be presented.

Unlike in Figure 5a, a deviation can be observed between the $P A H_{\text {sum }}$ and $P A H_{p k}$ graphs in Figure 6. This is due to the fact that above the conical region (represented by $\mathrm{OH}$ ), the two sides of the $P A H$ profiles merge to form a bimodal distribution, resulting in variation in trends of $P A H_{s u m}$ and $P A H_{p k}$. 


\subsection{Effect of methane and air flow rate}

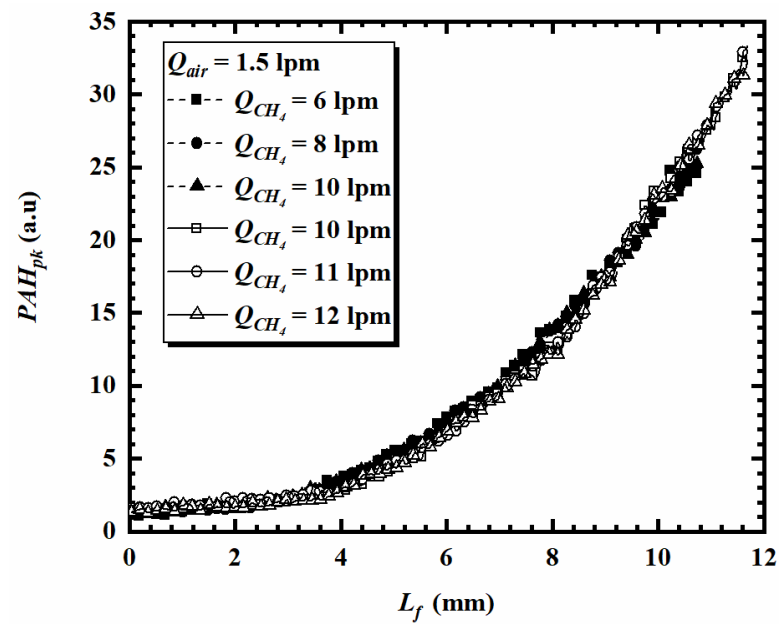

Figure 7: Effect of varying the methane $\left(\mathrm{CH}_{4}\right)$ flow rate on the PAH LIF signal, for a fixed air flow rate.

Figure 7 shows the effect of variation in methane flow rate, $Q_{C H 4}$, on the peak PAH intensity signal. It can be seen from Figure 7 that when the flow rate of methane is increased from $6 \mathrm{lpm}$ to $12 \mathrm{lpm}$ (a change of $100 \%$ ), no significant change in $P A H$ is obeserved. This shows that the effect of change in convection velocity had negligble influence on the PAH formation characteristics. This could potentially be explained by the fact that the mixing of reactants in IDF configuration is primarily diffusion-controlled. Hence, other factors, such as change in bulk velocity or change in the fluid shear stress (between the central and outer flows) might not have a significant impact. Therefore, when hydrogen is added to the fuel flow (up to $20 \%$ of the volume flow rate of methane, $Q_{C H 4}$ ), it can be safely assumed that the change in $\mathrm{PAH}$ characteritics is primarily due to $\mathrm{H}_{2}$ addition and not a consequence of the variations in bulk velocity values. The rate of change in $P A H$ (both peak and sum) with respect to the distance, presented here, is an indicative characteristic of the sooting tendency of the fuel mixture. It is clear from these results, if the air flow rate was kept constant, this $P A H$ growth rate (change in PAH LIF signal with respect to $L_{f}$ or $L_{h}$ ) will allow direct comparison of sooting tendencies (that is, PAH formation potential) of various fuel mixtures. 


\subsection{Hydrogen addition to the fuel $\left(\mathrm{CH}_{4}\right)$ stream}

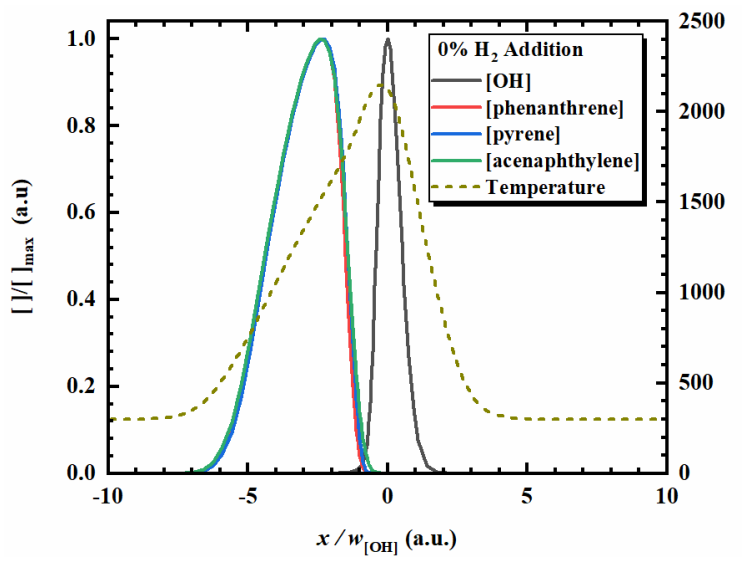

(a)

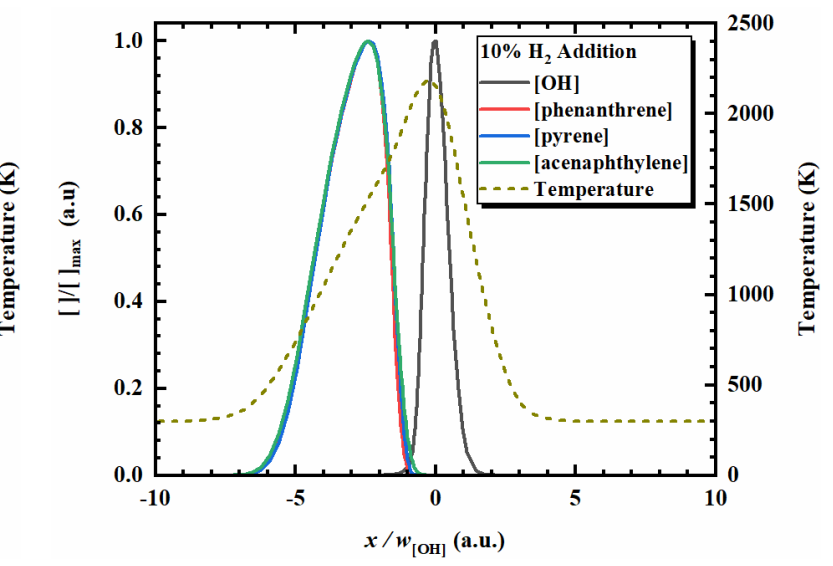

(b)

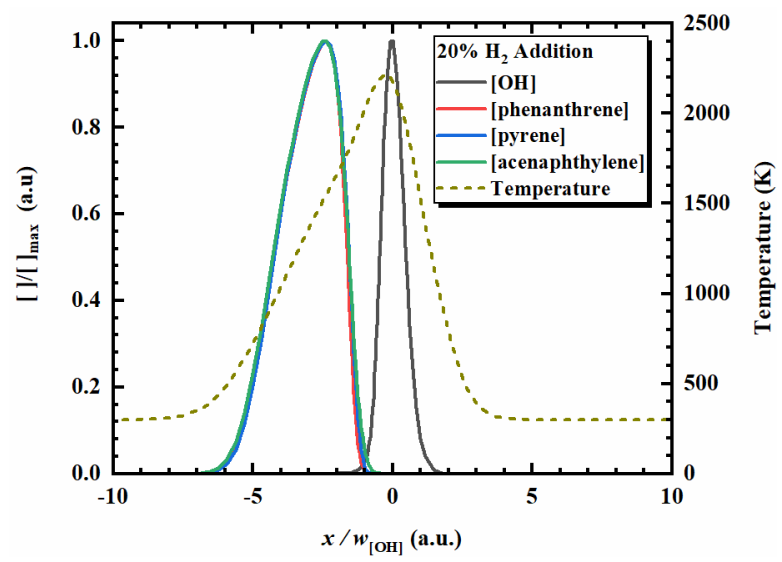

(c)

Figure 8: Axial profiles of [OH], three PAH species (3-ring: [phenanthrene], [acenaphthylene] and 4-ring: [pyrene]), and temperature for (a) $0 \%$, (b) $10 \%$ and (c) $20 \% \mathrm{H}_{2}$ addition, simulated using 1-D modelling of $\mathrm{CH}_{4}-\mathrm{H}_{2}$ flame. (Note: ' $x$ ' distance is normalised with FWHM of $\mathrm{OH}$ concentration, $w_{[0 H]}$ )

Figure 8 shows the axial profile concentrations of $\mathrm{OH}$, temperature and three PAH species phenanthrene ( 3 rings), acenaphthylene (3 rings) and pyrene ( 4 rings) - for three different $\mathrm{H}_{2}$ additions $(0,10$ and $20 \%)$, obtained from 1-D simulations of the methane-hydrogen flame. Simulation results for other mixture conditions are available, but for brevity only three conditions are presented. To allow accurate comparison, the $\mathrm{x}$-axis has been normalised with respect to the full width-half maximum $(\mathrm{FWHM})$ value of the $\mathrm{OH}$ profile, $w_{[\mathrm{OH}]}$. No significant change in the $\mathrm{PAH}$ line profile shape is observed with increasing levels of $\mathrm{H}_{2}$ addition. As expected, the peak temperature does show an increase, but only of about 50-70 K with increasing levels of $\mathrm{H}_{2}$ (maximum temperature data also shown in Table 1). 


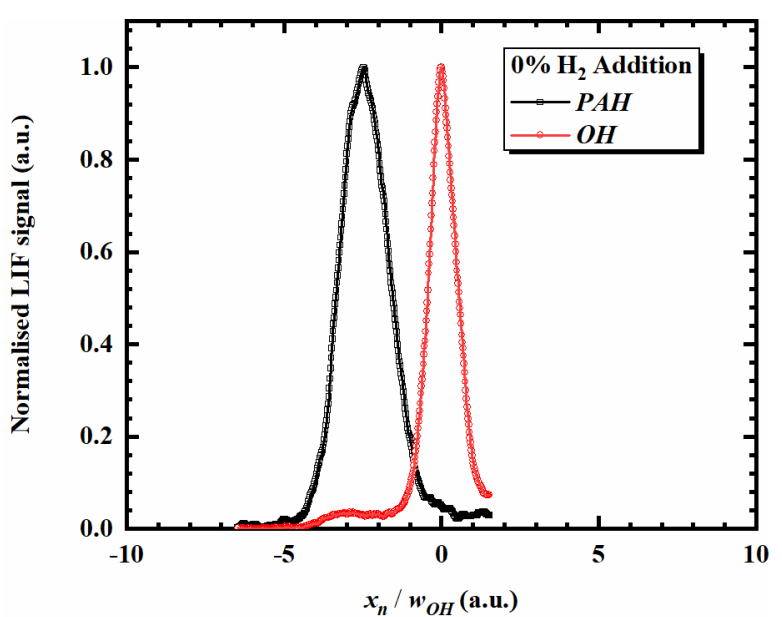

(a)

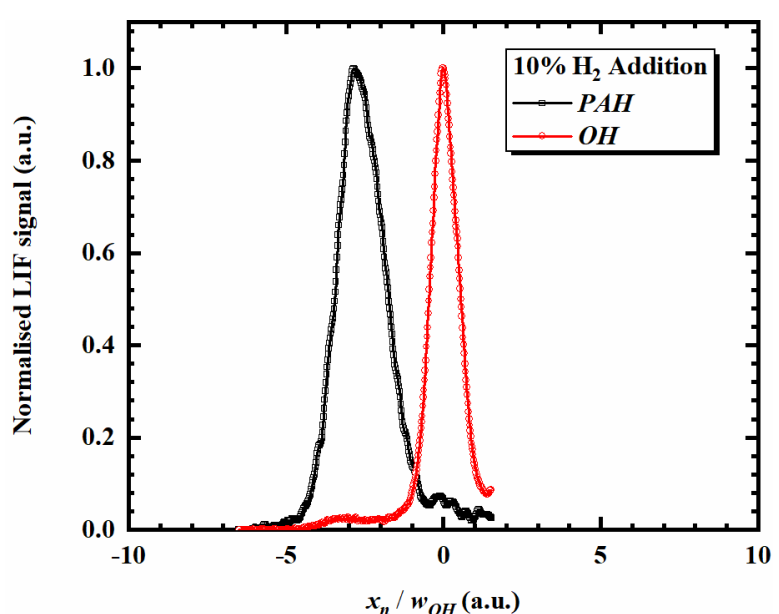

(b)

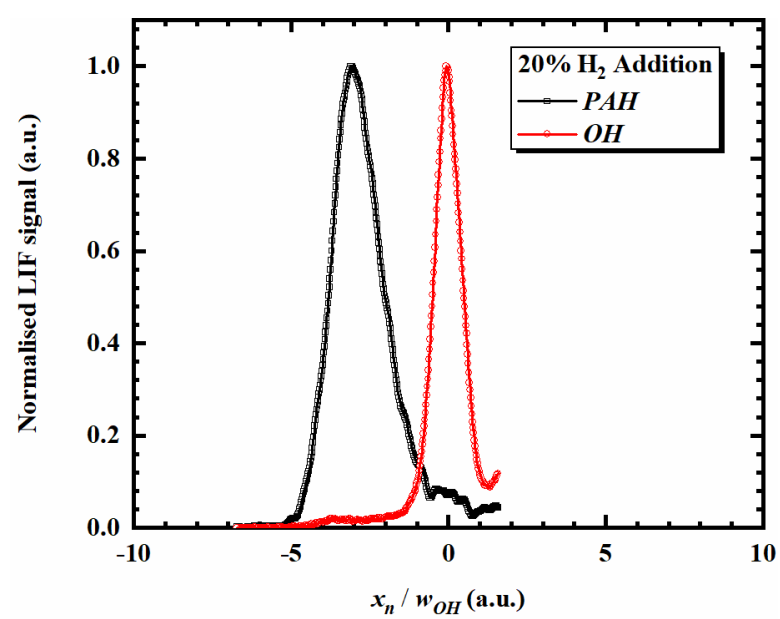

(c)

Figure 9: Line profiles of LIF signals $\mathrm{OH}$ and $\mathrm{PAH}$ along the normal, at a distance of $8 \mathrm{~mm}$ along the flame front $\left(L_{f}\right)$ for (a) $0 \%$, (b) $10 \%$ and (c) $20 \% \mathrm{H}_{2}$ addition.

Figure 9 shows the line profiles of $\mathrm{OH}$ and $\mathrm{PAH}$ species for three different $\mathrm{H}_{2}$ additions $(0,10$ and $20 \%)$ from experiments, obtained perpendicular to the flame front, at a length of $8 \mathrm{~mm}$ along the flame front. Similar to Figure 8, the $\mathrm{x}$-axis for Figure 9 has also been normalised with respect to the FWHM value of the $\mathrm{OH}$ line profile, $w_{\mathrm{OH}}$. A number of similarities can be observed between the computational and experimental line profiles presented in Figure 8 and 9. The normalised experimental PAH profiles similar to PAH concentration profiles from simulation start to increase at about 1 (a.u.) on the fuel side, away from the peak $\mathrm{OH}$ location for both sets of data. The experiments are limited in terms of resolving between individual PAH species, however the computational data shows that the different 3 and 4 ring PAH species have almost identical line profiles and are similarly affected by $\mathrm{H}_{2}$. Hence, the experimental data can be used to represent PAHs of a certain size group with reasonable accuracy. 


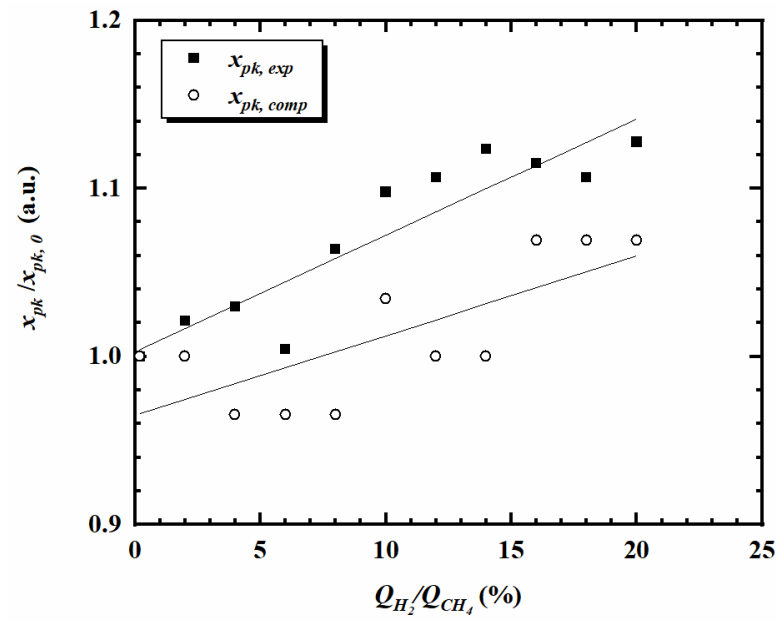

Figure 10: Comparison of the distance between OH peak and PAH peak $\left(x_{p k}\right)$ normalised with base case value $\left(x_{p k, o}\right)$, for various $\mathrm{H}_{2}$ addition levels in the methane flame, for both experimental and 1-D flame simulation studies. For experiments, data was obtained at a distance of $8 \mathrm{~mm}$ along the flame front $\left(L_{f}=\right.$ 8mm).

Figure 10 shows the variation in the normalised distance between the $\mathrm{OH}$ and the $\mathrm{PAH}$ peaks against different levels of $\mathrm{H}_{2}$ addition in the fuel $\left(\mathrm{CH}_{4}\right)$ stream, for experimental $\left(x_{p k, e x p}\right)$ and 1-D flame simulation $\left(x_{p k, c o m p}\right)$ studies, at a distance of $8 \mathrm{~mm}$ along the flame front, $L_{f}$. The inter-peak distance $x_{p k}$ was normalised with the $x_{p k}$ values of the base case, $x_{p k, o}$ (that is, $100 \% \mathrm{CH}_{4}$ and $0 \% \mathrm{H}_{2}$ ). It can be seen from the figure that both $x_{p k, \text { exp }}$ and $x_{p k, c o m p}$ show an overall increase with $\mathrm{H}_{2}$ addition. This observed trend is due to variations in adiabatic flame temperatures. Additionally, in an IDF configuration (present experimental work) combustion products and the unburnt fuel interact, which could potentially result in increased local mixture temperatures. The differences observed in the experimental and computational results could be attributed to the differences in flame configurations (2-D for experimental and 1-D for computational). 


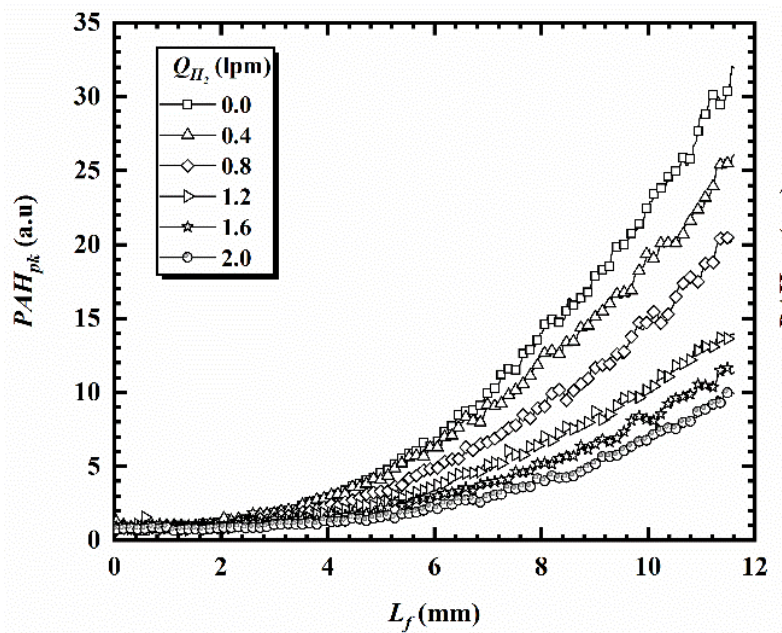

(a)

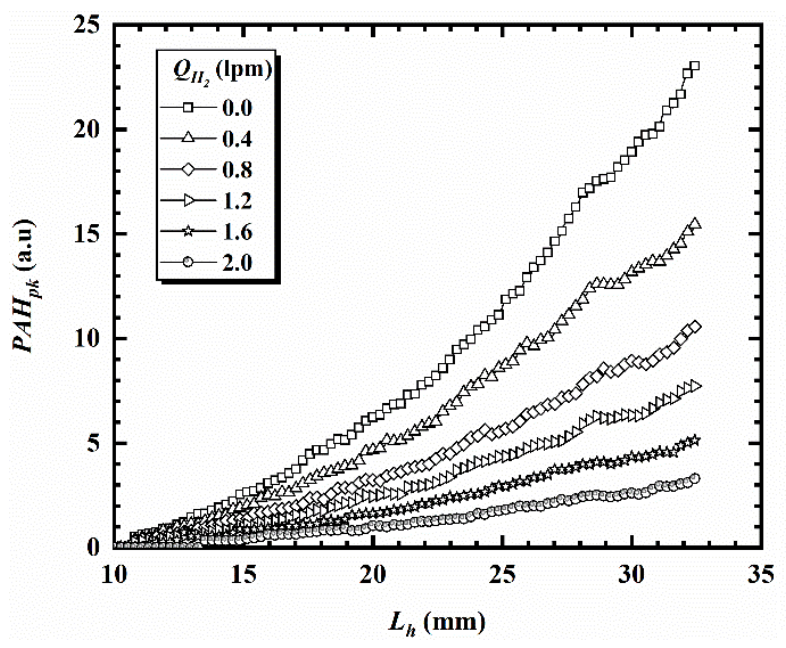

(c)

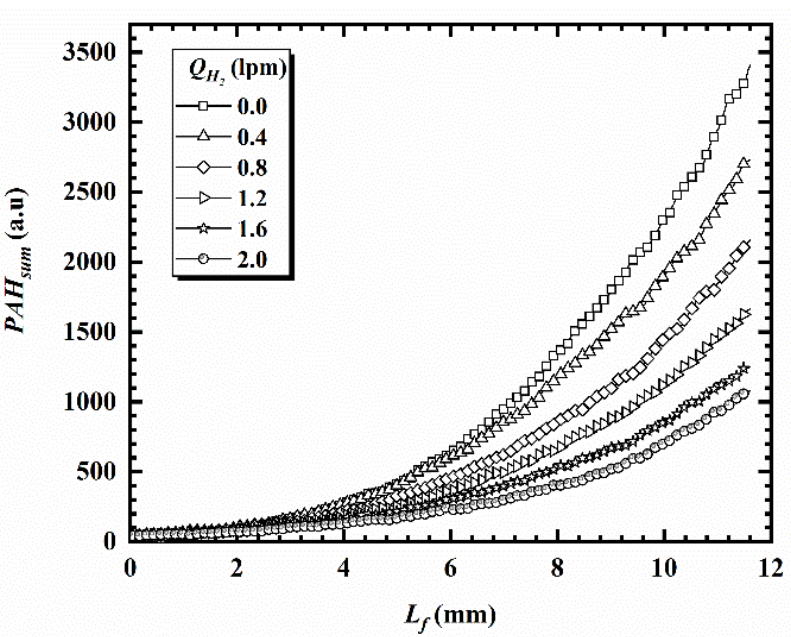

(b)

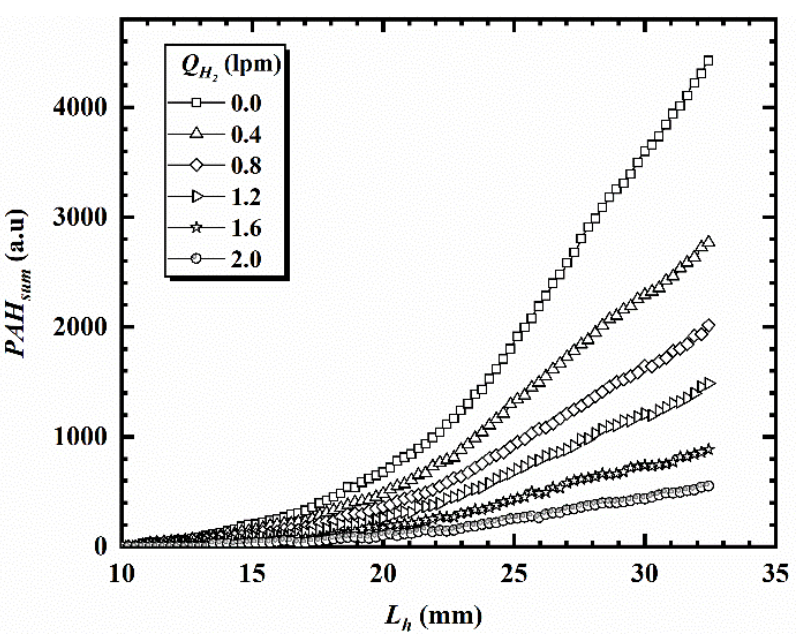

(d)

Figure 11: (a) Peak PAH LIF signal $\left(P A H_{p k}\right)$ and (b) cumulative sum of PAH line profile $\left(P A H_{s u m}\right)$ as a function of $L_{f}$ (length along the flame front), and (c) $P A H_{p k}$ and (d) $P A H_{\text {sum }}$ as a function of $L_{h}$ (vertical height above the burner lip), for various $\mathrm{H}_{2}$ addition levels.

Figure 11 shows the $P A H_{p k}$ and $P A H_{\text {sum }}$ for both the zoomed in (11a and 11b) and zoomed out (11c and 11d) camera configurations, for different levels of $\mathrm{H}_{2}$ addition in the fuel $\left(\mathrm{CH}_{4}\right)$ stream. The zoomed in data is presented as a function of distance along the flame front $\left(L_{f}\right)$, while the zoomed out data has been presented as a function of vertical height above the burner $\left(L_{h}\right)$, and shows PAHs at higher heights as compared to the zoomed in graphs. It can be observed from Figure 11a that the change in the PAH signal w.r.t. the length of the flame front is highest for the methane only flame, that is, without any $\mathrm{H}_{2}$ addition. As $\mathrm{H}_{2}$ is incrementally added, the rate of increase of $P A H_{p k}$ with respect to $L_{f}$, reduces. Similar trend in the reduction of $P A H$ with $\mathrm{H}_{2}$ is also observed at higher heights above the burner tip (Figure 11c-zoomed out configuration), as well as in the $P A H_{\text {sum }}$ graphs for both the configurations (Figures 
$11 \mathrm{~b}$ and 11d). This characteristic reduction in $P A H$ with $\mathrm{H}_{2}$ addition will be further discussed in the next few paragraphs.

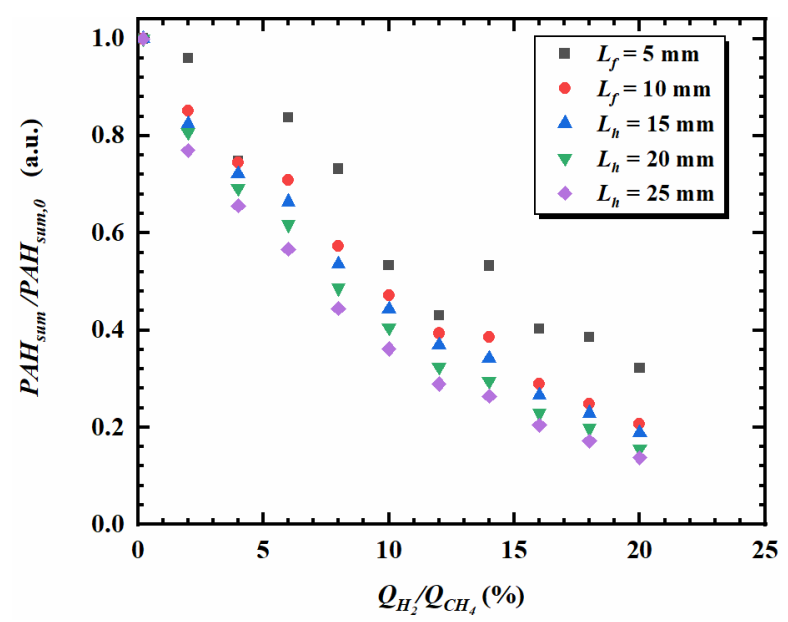

Figure 12: Variation in the $P A H_{\text {sum }}$ LIF signal normalised using base case value $\left(P A H_{\text {sum }, o}\right)$, as a function of percentage $\mathrm{H}_{2}$ addition, at five different heights above the burner lip.

Figure 12 shows the variation in the $P A H_{\text {sum }}$ at five fixed heights above the burner lip $\left(L_{f}\right.$ in the case of the 'zoomed in' configuration and $L_{h}$ in the case of the 'zoomed out' configuration), as a function of $\mathrm{H}_{2}$ addition. The $P A H_{\text {sum }}$ values have been normalised against the base case, $P A H_{\text {sum }, 0}$ (that is, $100 \% \mathrm{CH}_{4}$ and $0 \% \mathrm{H}_{2}$ ). It can be seen from the Figure 12 that $P A H_{\text {sum }}$ reduces monotonically with $\mathrm{H}_{2}$ addition at all the heights presented. Considering the reduction in the $\mathrm{PAH}$ signal due to $\mathrm{H}_{2}$ addition, it can be observed that at the lowest height presented of $5 \mathrm{~mm}\left(L_{f}\right)$ the change in the $P A H_{\text {sum }}$ is relatively lower (70\%) as compared to at the highest height where a reduction of almost $90 \%$ was observed with at the highest $\mathrm{H}_{2}$ addition level. As noted in previous studies, larger PAHs form at higher heights above the burner [49,51,52]. Since the addition of $\mathrm{H}_{2}$ impedes the formation of smaller PAHs, and hence preventing the formation of the larger PAHs, the effect of $\mathrm{H}_{2}$ addition is more significant at higher heights. 


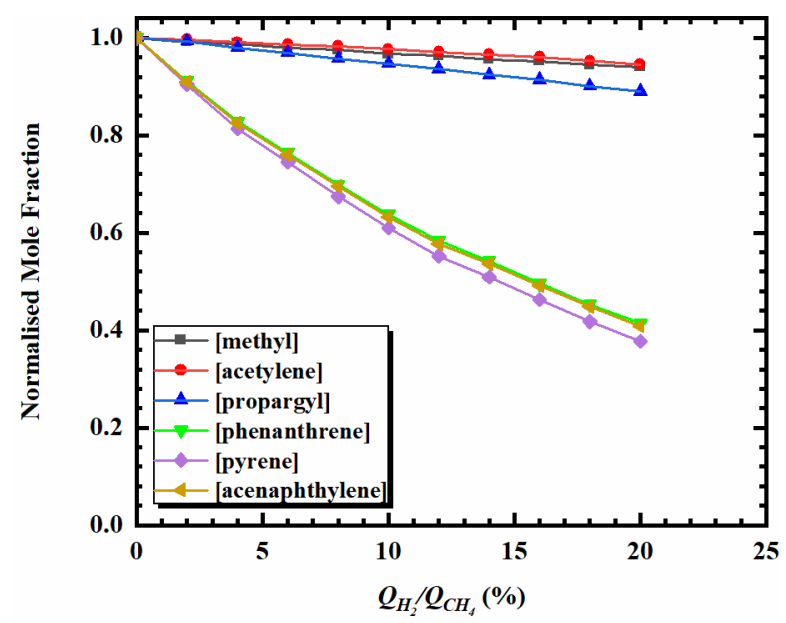

Figure 13: Variation in the concentrations of six species - methyl, acetylene, propargyl, acenaphthylene, phenanthrene, pyrene - as a function of $\mathrm{H}_{2}$ addition in fuel $\left(\mathrm{CH}_{4}\right)$ stream, simulated using 1-D modelling.

Figure 13 shows the variation in the concentrations of six species - methyl, acetylene, propargyl, acenaphthylene, phenanthrene, pyrene - as a function of $\mathrm{H}_{2}$ addition in fuel $\left(\mathrm{CH}_{4}\right)$ stream, simulated using 1-D computational modelling. It can be seen from the figure that the addition of $\mathrm{H}_{2}$ results in an almost 5\% reduction in methyl and acetylene, about 10\% reduction in propargyl and a corresponding $60 \%$ reduction in the three PAH species. Acetylene and propargyl are important species for the formation of first ring, benzene $\left(\mathrm{C}_{6} \mathrm{H}_{6}\right)$, which itself is an important intermediate for subsequent formation of larger rings [53,54]. Both acetylene and propargyl are building blocks of PAHs, involved in the primary reaction pathways of PAH formation. Acetylene is a crucial species of the HACA (hydrogen abstraction-acetylene addition) mechanism of PAH growth, while the recombination of propargyl is considered to be the most important cyclisation reaction in hydrocarbon flames $[52,55-$ 57]. Hence, a reduction in the concentration of acetylene and propargyl can have a significant impact on the concentration of the larger species like acenaphthylene, phenanthrene and pyrene, as can be observed in Figure 13.

The reduction in PAHs with $\mathrm{H}_{2}$ addition, as observed in both Figures 12 and 13, could be attributed to the added $\mathrm{H}_{2}$ chemically inhibiting $\mathrm{PAH}$ formation. The mole fraction of $\mathrm{OH}$ has been observed to increase with $\mathrm{H}_{2}$ addition to the fuel stream, both in this work and in previous studies [26,58]. Hence, it can be assumed that the increase in $\mathrm{OH}$ radicals could result in an increase in the rate of reactions which lead to higher oxidation rates of both acetylene and propargyl, hence reducing their availability to take part in the PAH formation reactions, and suppressing subsequent growth of PAHs. Another chemical effect associated with increasing the amount of $\mathrm{H}_{2}$ in the reacting zone is the increase in the reverse rate of the $\mathrm{H}$-abstraction reaction $\left(\mathrm{R}_{1}+\mathrm{H} \leftrightarrow \mathrm{R}_{2}+\mathrm{H}_{2}\right)$, which is a key reaction whereby $\mathrm{H}$ abstraction takes place to allow acetylene addition $[59,60]$. The abstraction of $\mathrm{H}$ atoms activates the surface sites of PAHs, and various hydrocarbon species such as acetylene and other PAHs then react with these active sites, hence propagating the surface growth process. The reduced $\mathrm{H}$-abstraction reaction rate reduces the number of sites available for acetylene addition, inhibiting surface growth of 
PAHs. Comparing Figures 12 and 13, it can be observed that the reduction in $P A H_{\text {sum }}$ at $5 \mathrm{~mm}$ along $L_{f}$ with maximum $\mathrm{H}_{2}$ addition is about $70 \%$, which is quite similar to the reduction in PAH concentration (approximately 60\%) observed from the flame simulation studies for the same $\mathrm{H}_{2}$ addition.

\section{Conclusions}

This paper presented an experimental methodology to analyse PAH formation characteristics in nonpremixed methane-air flames with systematic $\mathrm{H}_{2}$ addition, in an inverse diffusion flame, IDF, configuration. Simultaneous $\mathrm{OH}$ and PAH PLIF measurements were performed, and the PAH characteristics were described in relation to the $\mathrm{OH}$ profiles (which represented maximum temperature locations). This methodology enabled a comprehensive study of PAH formation characteristics with incremental $\mathrm{H}_{2}$ addition in non-premixed flames, and allowed meaningful comparisons to be made between the experiments and 1-D flame simulations. Some specific conclusions on the effect of $\mathrm{H}_{2}$ addition on PAH formation from this work are:

1. $P A H$ increased with increasing height above the burner attributed to both higher concentration of PAHs as well as formation of larger rings.

2. The distance between the $\mathrm{OH}$ and $\mathrm{PAH}$ peaks was observed to increase with increasing height above the burner. However, the PAH profile width remained largely similar beyond $4 \mathrm{~mm}$ above the burner tip. The change in the width below $4 \mathrm{~mm}$ was attributed to the radiative effects due to close proximity to the burner lip.

3. When considering $\mathrm{H}_{2}$ addition, both experimental and computational results showed similar PAH profile widths, with no significant change observed with $\mathrm{H}_{2}$ addition. However, the peak PAH location from the experimental campaign was observed to shift slightly away from the $\mathrm{OH}$ peak (representing maximum temperature locations) with increasing $\mathrm{H}_{2}$ addition.

4. The rate of change in $P A H$ with respect to the length of flame front (or height above burner) was highest for the methane only condition, with this rate reducing as $\mathrm{H}_{2}$ was incrementally added.

5. The reduction in $P A H$ was observed to be monotonic with $\mathrm{H}_{2}$ addition at all the heights above the burner tip, with higher reductions observed at higher heights above the burner. This was attributed to $\mathrm{H}_{2}$ preventing the formation of smaller PAHs at lower heights which would in turn impede the formation of larger PAHs at higher heights.

6. The percentage reduction in $P A H$ with $\mathrm{H}_{2}$ addition at $5 \mathrm{~mm}$ above the burner tip was of similar magnitude to that observed from 1-D flame simulations. This is because the 1-D flame simulations cannot capture resident time, and hence are most comparable to heights closer to the burner tip but away from high strain and heat loss region.

7. The reduction in $P A H$ with $\mathrm{H}_{2}$ addition was attributed to the increased oxidation of crucial species, such as acetylene and propargyl, hence reducing their availability for key PAH formation pathways. In addition, $\mathrm{H}_{2}$ reduced the rate of $\mathrm{H}$-abstraction, hence impeding growth reactions on PAHs due to reduction of active sites for PAH growth. 


\section{Acknowledgements}

The authors would like to acknowledge EPSRC (EP/P003036/1) and the Nigerian Petroleum Technology Development Fund (PTDF) for their financial support towards this work. NAKD acknowledges the financial support of the Qualcomm European Research Studentship Fund in Technology.

\section{Nomenclature}

\begin{tabular}{|l|l|}
\hline $\mathrm{CH}_{4}$ & Methane \\
\hline FOV & Field of view \\
\hline FWHM & Full Width Half Maximum \\
\hline $\mathrm{H}_{2}$ & Hydrogen Abstraction-Acetylene Addition \\
\hline ICCDs & Hydrogen \\
\hline IDF & Intensified Charge Coupled Devices \\
\hline$L_{f}$ & Inverse Diffusion Flames \\
\hline$L_{h}$ & Distance along the flame front \\
\hline lpm & Height above the burner \\
\hline NDF & Litres per minute \\
\hline OH & Normal Diffusion Flames \\
\hline PAH & Hydroxyl radical \\
\hline$P A H_{p k}$ & Polycyclic Aromatic Hydrocarbons \\
\hline$P A H_{s u m}$ & Peak value of PAH LIF profile \\
\hline PLIF & Cumulative of PAH LIF profile \\
\hline Q & Planar Laser Induced Fluorescence \\
\hline ROI & Volume flow rate \\
\hline SNR & Region of Interest \\
\hline$w_{P A H}$ & Signal to Noise Ratio \\
\hline$w_{O H}$ & FWHM of the experimental PAH profile \\
\hline$w_{[O H}$ & FWHM of the experimental OH profile \\
\hline$x_{p k}$ & FWHM of computational OH profile \\
\hline$x_{p k, 0}$ & The inter-peak distance between OH and PAH \\
\hline & The inter-peak distance $x_{p k}$ for pure methane case \\
\hline
\end{tabular}




\section{References}

[1] Lunde G, Bjorseth A. Polycyclic aromatic hydrocarbons in long-range transported aerosols. Nature 1977;268:518-9. doi:10.1038/268518a0.

[2] Abdel-Shafy $\mathrm{HI}$, Mansour MSM. A review on polycyclic aromatic hydrocarbons: Source, environmental impact, effect on human health and remediation. Egypt J Pet 2016;25:107-23. doi:10.1016/j.ejpe.2015.03.011.

[3] Harvey R. Polycyclic Aromatic Hydrocarbons: Chemistry and Carcinogenicity. 1st ed. Cambridge: Cambridge University Press; 1991.

[4] Velásquez M, Mondragón F, Santamaría A. Chemical characterization of soot precursors and soot particles produced in hexane and diesel surrogates using an inverse diffusion flame burner. Fuel 2013;104:681-90. doi:10.1016/j.fuel.2012.04.033.

[5] Santamaría A, Mondragón F, Molina A, Marsh ND, Eddings EG, Sarofim AF. FT-IR and1H NMR characterization of the products of an ethylene inverse diffusion flame. Combust Flame 2006;146:52-62. doi:10.1016/j.combustflame.2006.04.008.

[6] Shaddix CR, Williams TC. Measurements of the velocity field in laminar ethylene inverse jet diffusion flames. Combust Flame 2009;156:942-5. doi:10.1016/j.combustflame.2009.01.017.

[7] Mikofski MA, Williams TC, Shaddix CR, Blevins LG. Flame height measurement of laminar inverse diffusion flames. Combust Flame 2006;146:63-72. doi:10.1016/j.combustflame.2006.04.006.

[8] Yamamoto K, Takemoto M. Reductions of PAH and Soot by Center Air Injection. Environments 2014;1:42-53. doi:10.3390/environments1010042.

[9] Liu F, Hua Y, Wu H, Lee CFF, Li Y. Experimental investigation of polycyclic aromatic hydrocarbons growth characteristics of gasoline mixed with methanol, ethanol, or n-butanol in laminar diffusion flames. Energy and Fuels 2018;32:6823-33. doi:10.1021/acs.energyfuels.8b00693.

[10] Zhang Y, Wang L, Liu P, Guan B, Ni H, Huang Z, et al. Experimental and kinetic study of the effects of $\mathrm{CO} 2 \mathrm{and} \mathrm{H} 2 \mathrm{O}$ addition on $\mathrm{PAH}$ formation in laminar premixed $\mathrm{C} 2 \mathrm{H} 4 / \mathrm{O} 2 / \mathrm{Ar}$ flames. Combust Flame 2018;192:439-51. doi:10.1016/j.combustflame.2018.01.050.

[11] Wu J, Song KH, Litzinger T, Lee SY, Santoro R, Linevsky M. Reduction of PAH and soot in premixed ethylene-air flames by addition of dimethyl ether. Combust Sci Technol 2006;178:837-63. doi:10.1080/00102200500269942.

[12] Sidebotham GW, Glassman I. Flame temperature, fuel structure, and fuel concentration effects on soot formation in inverse diffusion flames. Combust Flame 1992;90:269-83. doi:10.1016/0010-2180(92)90088-7.

[13] Bejaoui S, Mercier X, Desgroux P, Therssen E. Laser induced fluorescence spectroscopy of aromatic species produced in atmospheric sooting flames using UV and visible excitation wavelengths. Combust Flame 2014;161:2479-91. doi:10.1016/j.combustflame.2014.03.014.

[14] Blevins LG, Fletcher RA, Benner BA, Steel EB, Mulholland GW. The existence of young soot in the exhaust of inverse diffusion flames. Proc Combust Inst 2002;29:2325-33. doi:10.1016/S1540-7489(02)80283-8. 
[15] Dobbins RA. Hydrocarbon nanoparticles formed in flames and diesel engines. Aerosol Sci Technol 2007;41:485-96. doi:10.1080/02786820701225820.

[16] Hansen N, Cool TA, Westmoreland PR, Kohse-Höinghaus K. Recent contributions of flamesampling molecular-beam mass spectrometry to a fundamental understanding of combustion chemistry. Prog Energy Combust Sci 2009;35:168-91. doi:10.1016/j.pecs.2008.10.001.

[17] Ju EL, Oh KC, Shin HD. Soot formation in inverse diffusion flames of diluted ethene. Fuel 2005;84:543-50. doi:10.1016/j.fuel.2004.11.003.

[18] Yamamoto K, Takemoto M. Measurement of PAH and soot of diffusion flames in a triple port burner. Fuel Process Technol 2013;107:99-106. doi:10.1016/J.FUPROC.2012.06.006.

[19] Choi SK, Choi BC, Lee SM, Choi JH. The effect of liquid fuel doping on PAH and soot formation in counterflow ethylene diffusion flames. Exp Therm Fluid Sci 2015;60:123-31. doi:10.1016/j.expthermflusci.2014.08.008.

[20] Golea D, Rezgui Y, Guemini M, Hamdane S. Reduction of PAH and soot precursors in benzene flames by addition of ethanol. J Phys Chem A 2012;116:3625-42. doi:10.1021/jp211350f.

[21] Singh P, Sung CJ. PAH formation in counterflow non-premixed flames of butane and butanol isomers. Combust Flame 2016;170:91-110. doi:10.1016/j.combustflame.2016.05.009.

[22] Choi J-H, Hwang C-H, Choi SK, Lee SM, Lee WJ, Jang SH, et al. Impacts of hydrogen addition on micro and nanostructure of soot particles formed in $\mathrm{C} 2 \mathrm{H} 4$ /air counter diffusion flames. Int J Hydrogen Energy 2016;41:15852-8. doi:10.1016/J.IJHYDENE.2016.04.158.

[23] Mze Ahmed A, Mancarella S, Desgroux P, Gasnot L, Pauwels J-F, El Bakali A. Experimental and numerical study on rich methane/hydrogen/air laminar premixed flames at atmospheric pressure: Effect of hydrogen addition to fuel on soot gaseous precursors. Int J Hydrogen Energy 2016;41:6929-42. doi:10.1016/J.IJHYDENE.2015.11.148.

[24] De luliis S, Maffi S, Migliorini F, Cignoli F, Zizak G. Effect of hydrogen addition on soot formation in an ethylene/air premixed flame. Appl Phys B Lasers Opt 2012;106:707-15. doi:10.1007/s00340-012-4903-2.

[25] Gu M, Chu H, Liu F. Effects of simultaneous hydrogen enrichment and carbon dioxide dilution of fuel on soot formation in an axisymmetric coflow laminar ethylene/air diffusion flame. Combust Flame 2016;166:216-28. doi:10.1016/j.combustflame.2016.01.023.

[26] Guo H, Liu F, Smallwood GJ, Gülder ÖL. Numerical study on the influence of hydrogen addition on soot formation in a laminar ethylene-air diffusion flame. Combust Flame 2006;145:324-38. doi:10.1016/j.combustflame.2005.10.016.

[27] Gülder ÖL, Snelling DR, Sawchuk RA. Influence of hydrogen addition to fuel on temperature field and soot formation in diffusion flames. Symp Combust 1996;26:2351-8. doi:10.1016/S0082-0784(96)80064-6.

[28] Park S, Wang Y, Chung SH, Sarathy SM. Compositional effects on PAH and soot formation in counterflow diffusion flames of gasoline surrogate fuels. Combust Flame 2017;178:46-60. doi:10.1016/j.combustflame.2017.01.001.

[29] Lee SM, Yoon SS, Chung SH. Synergistic effect on soot formation in counterflow diffusion flames of ethylene-propane mixtures with benzene addition. Combust Flame 2004;136:493500. doi:10.1016/j.combustflame.2003.12.005. 
[30] Wei M, Liu J, Guo G, Li S. The effects of hydrogen addition on soot particle size distribution functions in laminar premixed flame. Int J Hydrogen Energy 2016;41:6162-9. doi:10.1016/J.IJHYDENE.2015.10.022.

[31] Liu F, Ai Y, Kong W. Effect of hydrogen and helium addition to fuel on soot formation in an axisymmetric coflow laminar methane/air diffusion flame. Int J Hydrogen Energy 2014;39:3936-46. doi:10.1016/j.ijhydene.2013.12.151.

[32] Yuan C, Han C, Liu Y, He Y, Shao Y, Jian X. Effect of hydrogen addition on the combustion and emission of a diesel free-piston engine. Int J Hydrogen Energy 2018;43:13583-93. doi:10.1016/j.jjhydene.2018.05.038.

[33] Koten $\mathrm{H}$. Hydrogen effects on the diesel engine performance and emissions. Int J Hydrogen Energy 2018;43:10511-9. doi:10.1016/j.ijhydene.2018.04.146.

[34] Talibi M, Balachandran R, Ladommatos N. Influence of combusting methane-hydrogen mixtures on compression-ignition engine exhaust emissions and in-cylinder gas composition. Int J Hydrogen Energy 2017;42:2381-96. doi:10.1016/j.ijhydene.2016.10.049.

[35] Park SH, Lee KM, Hwang CH. Effects of hydrogen addition on soot formation and oxidation in laminar premixed C2H2/air flames. Int J Hydrogen Energy 2011;36:9304-11. doi:10.1016/j.ijhydene.2011.05.031.

[36] Zizak G, Cignoli F, Montas G, Beneccchi S, Dondè R. Detection of aromatyc hydrocabons in the exhaust gases of a i.c. engine by laser-induced fluorescence technique. Recent Res Devel Appl Spectro 1996;1.

[37] Xiao J, Austin E, Roberts WL. Relative polycyclic aromatic hydrocarbon concentrations in unsteady counterflow diffusion flames. Combust Sci Technol 2005;177:691-713. doi:10.1080/00102200590917239.

[38] Vander Wal RL. LIF-LII measurements in a turbulent gas-jet flame. Exp Fluids 1997;23:281-7. doi:10.1007/s003480050112.

[39] Chakraborty A, Chakravarthy SR. Formation of Soot in Ethylene - Air Partially Premixed Flames Over a Wide Range of Premixedness. J Eng Gas Turbines Power 2018;139:1-6. doi:10.1115/1.4037580.

[40] Berman IR. Handbook of Fluorescence Spectra of Aromatic Molecules. second edi. New York: Academic Press; 1971.

[41] Wang Y, Park S, Sarathy SM, Chung SH. A comparative study on the sooting tendencies of various 1-alkene fuels in counterflow diffusion flames. Combust Flame 2018;192:71-85. doi:10.1016/j.combustflame.2018.01.033.

[42] Ciajolo A, Tregrossi A, Barbella R, Ragucci R, Apicella B, de Joannon M. The relation between ultraviolet-excited fluorescence spectroscopy and aromatic species formed in rich laminar ethylene flames. Combust Flame 2001;125:1225-9. doi:10.1016/S0010-2180(01)00242-5.

[43] Verhoeven LM, de Andrade Oliveira MH, Lantz A, Li B, Li ZS, Luijten CCM, et al. A numerical and experimental study of Polycyclic Aromatic Hydrocarbons in a laminar diffusion flame. Proc Combust Inst 2013;34:1819-26. doi:10.1016/J.PROCI.2012.06.016.

[44] Vander Wal RL, Jensen KA, Choi MY. Simultaneous laser-induced emission of soot and polycyclic aromatic hydrocarbons within a gas-jet diffusion flame. Combust Flame 
1997;109:399-414. doi:10.1016/S0010-2180(96)00189-7.

[45] Eckbreth AC. Laser Diagnostics for Combustion Temperature and Species. 2nd ed. Amsterdam: Gordon and Breach Publishers; 1996.

[46] Smyth KC, Shaddix CR, Everest DA. Aspects of soot dynamics as revealed by measurements of broadband fluorescence and flame luminosity in flickering diffusion flames. Combust Flame 1997;111:185-207. doi:10.1016/S0010-2180(97)00017-5.

[47] Goodwin DG, Moffat HK, Speth RL. Cantera: An Object-oriented Software Toolkit for Chemical Kinetics, Thermodynamics, and Transport Processes. Version 2.2.0 2017. doi:10.5281/zenodo.48735.

[48] Appel J, Bockhorn H, Frenklach M. Kinetic modeling of soot formation with detailed chemistry and physics: laminar premixed flames of C2 hydrocarbons. Combust Flame 2000;121:122-36. doi:10.1016/S0010-2180(99)00135-2.

[49] Mikofski MA, Williams TC, Shaddix CR, Fernandez-Pello AC, Blevins LG. Structure of laminar sooting inverse diffusion flames. Combust Flame 2007;149:463-78. doi:10.1016/J.COMBUSTFLAME.2007.01.006.

[50] Beretta F, Cincotti V, D'Alessio A, Menna P. Ultraviolet and visible fluorescence in the fuel pyrolysis regions of gaseous diffusion flames. Combust Flame 1985;61:211-8. doi:10.1016/0010-2180(85)90102-6.

[51] Hepp H, Siegmann K, Sattler K. New aspects of growth mechanisms for polycyclic aromatic hydrocarbons in diffusion flames. Chem Phys Lett 1995;233:16-22. doi:10.1016/00092614(94)01433-V.

[52] Richter $\mathrm{H}$, Howard J. Formation of polycyclic aromatic hydrocarbons and their growth to soot a review of chemical reaction pathways. Prog Energy Combust Sci 2000;26:565-608. doi:10.1016/S0360-1285(00)00009-5.

[53] Bockhorn H, Schäfer T. Growth of Soot Particles in Premixed Flames by Surface Reactions, 1994, p. 253-74. doi:10.1007/978-3-642-85167-4_14.

[54] Wang $\mathrm{H}$, Frenklach $\mathrm{M}$. A detailed kinetic modeling study of aromatics formation in laminar premixed acetylene and ethylene flames. Combust Flame 1997;110:173-221. doi:10.1016/S0010-2180(97)00068-0.

[55] Frenklach M, Wang H. Detailed modeling of soot particle nucleation and growth. Symp Combust 1991;23:1559-66. doi:10.1016/S0082-0784(06)80426-1.

[56] Kislov V V., Sadovnikov Al, Mebel AM. Formation Mechanism of Polycyclic Aromatic Hydrocarbons beyond the Second Aromatic Ring. J Phys Chem A 2013;117:4794-816. doi:10.1021/jp402481y.

[57] Miller JA, Melius CF. Kinetic and thermodynamic issues in the formation of aromatic compounds in flames of aliphatic fuels. Combust Flame 1992;91:21-39. doi:10.1016/00102180(92)90124-8.

[58] PANDEY P, PUNDIR B, PANIGRAHI P. Hydrogen addition to acetylene-air laminar diffusion flames: Studies on soot formation under different flow arrangements. Combust Flame 2007;148:249-62. doi:10.1016/j.combustflame.2006.09.004. 
[59] Park S-H, Choi MY, Yozgatligil A. Nanostructure of Soot Collected from Ethanol Droplet Flames in Microgravity. Combust Sci Technol 2009;181:1164-86. doi:10.1080/00102200903074154.

[60] Frenklach M. Reaction mechanism of soot formation in flames. Phys Chem Chem Phys 2002;4:2028-37. doi:10.1039/b110045a. 